\title{
Built Heritage Information Modelling/Management. Research Perspectives
}

\author{
Stefano Della Torre and Alessandra Pili
}

\begin{abstract}
The paper deals with the research issues concerning Historic Building Information Modelling, developing the outcomes of the national project BHIMM, carried out in 2017. The topic has a strategic value, as the relevant new tools enable the kind of Knowledge Management required by the Planned Conservation vision. The key point is the step from implementing BIM authoring software to build a single parametric model, to the definition of several domain-specific parametric models fit for each of the many activities involved in built heritage conservation process. As designed for specific aims, the models can differ both in accuracy and in identification of the objects. This vision moves the research agenda towards exchange platforms and semantic interoperability, pointing out the development of specific ontologies as a crucial task to be carried out in the next years.
\end{abstract}

Keywords Historic BIM · Parametric models $\cdot$ Conservation process · Ontologies

\section{Introduction}

The implementation of digital informative modeling on historic buildings are a quite recent research topic, whose developments started more or less ten years ago, producing growing scientific literature. Undoubtedly the process can be described as a technological transfer process that is the transfer of BIM from the construction industry field to the cultural heritage world, where innovation often happens through the reuse of practices. This entails theoretical and practical issues, as the new tools go into a frame of accustomed attitudes, often without changing mind and underestimating, or wasting, the making of the new procedures and techniques in order to achieve targets unsought before. Both academics and the industry are still looking for

S. Della Torre $(\bowtie) \cdot$ A. Pili

Architecture, Built Environment and Construction Engineering-ABC Department, Politecnico di Milano, Milan, Italy

e-mail: stefano.dellatorre@polimi.it 
the most effective roadmap to a real implementation of digital techniques on this very peculiar market. Nevertheless, two important premises deserve to be highlighted, in order to show the vision, the making and some biases of these researches.

The first premise of the development of Historic BIM has been the availability of digital survey techniques, ending up in 3D models characterized by better and better accuracy. The evolution of acquisition tools in Geomatics field has been the precondition for the capability of 3D models to support the management of existing buildings. Architects and Conservators got accustomed with Point-clouds, while the costs of automatic survey became competitive with the costs of direct measurements. Then, a large deal of the literature on HBIM deals with documentation and the step from surveying to modelling.

The second premise concerns the step from restoration to preventive conservation, which implied not only a focus on prevention and maintenance, but also a growing interest for knowledge management and databases supporting long-term care activities. Therefore, HBIM answers a twofold expectation on digital innovation, on one side looking for more accurate survey and documentation, on the other side looking for a more effective storage and retrieval of information. HBIM should exactly bridge these two opportunities, giving the way to opportunities not yet put into practice. If this is the research goal, an integrated multidisciplinary approach is a basic condition: exactly what the BHIMM project aimed to set up.

BHIMM (Built Heritage Information Modeling Management) project was launched in 2011, when this kind of researches were still not so popular worldwide, as a PRIN granted by the Italian Ministry of University and Research (Della Torre 2017). It involved six Research Units: besides Politecnico di Milano, the Universities of Rome, Genoa and Brescia, Politecnico di Torino and the Bari based unit of CNR. The research groups involved academics from different fields (architectural conservation, construction technology, building physics, structural analysis, survey and documentation...). BIM techniques as implemented in the heritage domain have been tested on several outstanding historic buildings: for instance, the basilica of S. Maria di Collemaggio in L'Aquila, damaged by earthquake in 2009 and under reconstruction (Oreni et al. 2014; Trani et al. 2015; Brumana et al. 2018); Milan Cathedral (Fassi et al. 2015); the Albergo dei Poveri in Genua (Musso and Franco 2014; Napoleone 2017; Vecchiattini and Babbetto 2017); Masegra Castle in Sondrio (Barazzetti et al. 2015). Different modelling solutions were tested, and in many cases not only the most popular BIM authoring software, but other modelling software was used, in order to overcome the "rigidity" of the BIM. Almost all the activities have been explored, which follow each other along the cyclic management process of an historic building, with the perspective of making those activities as much as possible digital by means of interoperable techniques. The Research Unit from Rome developed a deeper investigation on ontologies for cultural heritage, laying the bases for important further researches still developing (see below).

The outcomes of BHIMM project contributed to a renovated approach and opened to further research in the direction of more performing technological transfer of BIM potentialities to the domain of historic buildings. 


\section{Built Cultural Heritage Process}

The many pilot researches carried out in the frame of BHIMM project on several Italian historic buildings demonstrated that the transition from the traditional representation by $2 \mathrm{D}$ views associated with a restoration project to a $3 \mathrm{D}$ parametric model cannot be just a matter of tools and procedures to be customized: instead, it is necessary to understand the making of parametric tools to renovate the whole heritage conservation and valorization process.

According to the most established literature, parametric objects should: contain geometric information and associated data and rules; have non-redundant geometry, which allows for no inconsistencies; have parametric rules, which automatically modify associated geometries when inserted into a building model, or when changes are made to associated objects; have the ability to be defined at different levels of aggregation; have the ability to receive, or to export, or to link sets of attributes (such as structural materials, acoustic data, energy data, and cost) to other applications and models. (Eastman et al. 2011: 626). Parametric modeling refers to a virtual construction with fully defined objects that know where they belong, how they relate to other objects and what they consist of (Barazzetti 2016).

The transition from drawings to parametric modeling is parallel with the transition from restoration as an event to conservation as a process (we use to speak of planned conservation). Therefore, it is a transition from a scheme that used to see restoration as a construction process (on existing premises rather than on free land), to the vision of a long-term process, in which many different activities (management, maintenance, monitoring, conservation, heating, restoration, etc.) are carried out by different actors, who need overcome asymmetries and cognitive gaps as they exchange a lot of information.

The conservation process of built cultural heritage is radically different from the construction process, and therefore substantial challenges arise in implementing BIM tools in this context. The topic of Built Heritage Information Modeling, or Historic BIM, requires to be approached through a deep understanding of the processes, well before working on the questions concerning the development of the tools. Researches of this kind have been carried out as the foundation of proposals aimed at innovating the practices in the preservation field (Della Torre 2018). The point is the continuity of the process, which requires an important investment in knowledge management and digitalization of the procedures. Conservation works on protected buildings entail continuity in knowledge management, so that they require at any step a high level of information and description. In the best case, the scientific report produced by a previous intervention should be available, implemented by following maintenance and management activities (Della Torre et al. 2018). 


\section{Survey and LoDs}

As the available BIM tools have been developed first to design and assemble serial building components, they can hardly deal with the irreducible variety of ancient buildings, which are still in use although well beyond the limits of their service life. Once a building had been recognized as heritage, its conservation has to comply with the dimensions of authenticity.

The basic problems emerging when dealing with the step from point-clouds to parametric models for architectural conservation have been largely dealt with in the literature:

- collected data cannot be limited to external surfaces of the objects, which have to be investigated and someway represented also by their thickness, layers and internal features, characterizing elements as three-dimensional not only under the geometric point of view, but also for materials and techniques;

- as the point-cloud has to be converted in models made of discrete and significant objects, corresponding to the needed operations for design, computation or documentation purposes: given the irregular shapes of historical buildings, NURBS (non-uniform rational B-splines) curves and surfaces have supplied a satisfactory solution, which enables to keep the level of accuracy obtained thanks to the advanced surveying techniques;

- the typified components downloaded from libraries, provided by commercial parametric software, can be enriched and customized (Dore and Murphy 2013; Oreni et al. 2013), but any historic building is the outcome of construction processes, besides changes and layering in progress of time, which produce the variety that is just the core of the recognition of authenticity, and therefore of value. The question of harmonizing the oneness character with typology approach is surely not new, as this was one of the most discussed topics in Conservation theory. The solution of producing individual objects embedded in the model instead in the software library has been successfully explored, but it entails giving up a series of possible automations.

The available readymade families of elements typical of historic architecture, classified by periods, often coming from the plates of architectural treatises, can surely help to make better-looking and more realistic 3D models, but if these models should serve to enhance data sharing, there is the risk of disseminating a level of detail, which is not exhaustive for the management of the whole process.

The trend, from both the research and industry sides, has been to bridge the gap between survey and parametric modeling, empowering the most popular software tools. Nevertheless, also the sense of this step has to be clarified, by means of some reflections on operational needs, that is on the required levels of description and information. In the field the acronym LoD is used, meaning "Level of Development" or "Level of Detail". 
Being definitely different from the design of a new building, the work carried out on an existing building, especially when it is dealt with as a heritage object to be conserved and not just retrofitted, is not progressive: it is a matter of reverse engineering or downloading from data banks, and "required functionality determines the LoD and the resulting cost and effort associated with BIM creation" (Volk et al. 2014).

For the Italian norm UNI 11337 Stefano Della Torre suggested a definitely peculiar approach to LODs, overturning the parallelism with the progressive LODs described for the design of new constructions: BIM practices as derived from the new construction lead to deal with details and accuracy in developing terms, from rough to detailed, as the design and construction process goes on. The Italian norm proposes to think in terms of different parallel models derived from one accurate survey, and the use of the terms "level", or "grade" does not mean any progression from one level to the next one, but just differences in terms of the detail or accuracy consistent with the purposes and the characteristics of the parametric model required by each domain. This enables to embody the historic complexity since the starting phase (Brumana et al. 2019) to better support the assessment and decision making, to limit the unexpected expensive interruption of the construction site, adopting heritage monitoring as a strategy for planned conservation across the time (Fregonese et al. 2018).

\section{Model, Platform, Common Data Environment}

The conceptual distinction between a (unique) interoperable model and the concept of platform, which enables data exchange among several "domain specific" parametric models, or BIMs, is a basic point established in BIM research. Rothenberg said that "a model represents reality for the given purpose, the model is an abstraction of reality in the sense that it cannot represent all aspects of reality" (Rothenberg 1989). In other words, a single model is not enough to represent the reality.

Domain specific models (i.e., BIM for Architectural design, Structural analysis, Energy analysis, construction and site design, cost analysis, management, maintenance, etc.) will undoubtedly perform better than the huge single model, which should also work as the exchange platform. Some experience can already be shown, e.g. focused on energy retrofitting (Gholami et al. 2015) and maintenance (Kiviniemi and Codinhoto 2014).

For each model, a different individual identification of BIM objects can be carried out; each specific model should download from the general data base just the useful data, and upload its outputs in order to make them available for other domains through the "platform", or to say better the Common Data Environment (CDE).

The high level of detail in HBIM models may not be needed in some technical domains even if related to cultural heritage. For example, single domains such as structural analyses, energy simulations, behavioral studies, cost computation, etc. could refer to simplified versions of the model. However, sometimes even single technical activities require an advanced level of detail, as well as different definitions 
of the parametric objects. For example, sometimes a structural or energy analysis may need to take into account an entire element, such as a wall or a column, and sometimes just its layers, parts, stones, etc. At other times, the entire level of detail of the model would be required for other kinds of analyses (Della Torre et al. 2017).

An example may clarify this point. As dealing with a wooden beam floor in an historic building, laser scanning produces a point cloud, which shows a non-regular geometry. Usually, beams are seen as inflected in the points-cloud, due to an elastic reaction to actual loads, and/or to permanent inelastic deformations, and/or to their original shapes. As a result, each beam is different. Furthermore, the soffit is often decorated by paintings. The question is which features should be reflected in the parametric model. But the problem could be put otherwise, if we imagine not one comprehensive model, but special parametric models fit for each activity. Then, the question concerns the purpose of the models, and which features should be present in the parametric environments.

So in this example, we can imagine to split the problem in at least three branches: the architectonic perspective, dealing with the values, the uses and the performances of the spaces; the structural perspective, dealing with the load-bearing capacity of the beams and their efficiency; the conservator-restorer's perspective, dealing with the conservation issues of the surfaces and the materials. The architectural project needs a complete representation of all the features concerning spatial and performance issues and cultural values. But for these aims in the deformation, or irregular shape of the beams has no relevance. This means that a survey can be fit for such a model even if the accuracy is in the order of some centimeters, as it happens with regular laser scanning. The structural analyses take into account the quality of the wooden beams, but as these deformations have less than second-order effects on the stresses, there is no sense in overloading the parametric models with these details, although considered in the interpretation of the results. Again, the accuracy of some centimeters is enough. In the perspective of conservation-restoration issues, however, the shapes and the thin layers of the surfaces are definitely important: the geometry is needed as fine as possible, so that a better surveying technique may be required, such as digital photogrammetry, in order to reach an accuracy in the order of millimeters. This geometry may be usefully turned into a parametric model, because undoubtedly the work to do benefits from dealing with fully defined objects, knowing their position, consistency and relationships.

So, it is possible to imagine different BIMs, each one related to the same CDE, with elements described with different accuracy in one or more point-clouds. This can be a direction for future research, focusing on exchange procedures and dynamic shift from CDE to single BIMs, and related costs and required skills.

The vision of several BIMs referring to a common data environment has been argued as the way to ensure the highest interoperability (Laakso and Kiviniemi 2012). It is also the way to carry on a very important change in heritage field, because the required anticipation of detailed investigation, as well as the availability of tools that enable a continuous control, will enhance the quality of the whole process. 


\section{Towards Semantic Interoperability}

Interoperability is the ability of a system to understand and to be understood when it interfaces with other systems. If two systems have syntactic interoperability, they can communicate with each other and exchange data. Instead, semantic interoperability allows the system to automatically interpret information. In this case, the content of the information is unambiguously defined: what has been transmitted is the same as what is understood. The aim of further HBIM research is to define open standards for semantic interoperability among the various models concerning Cultural Heritage activities. The mandatory premise in order to enable interoperability among diverse information systems is the definition of specific ontologies (Doerr 2009; Noardo 2015; Bruseker et al. 2017).

Ontologies, as computer systems, work in a hierarchical way where the classes are descripted from general to detail (Kupcík et al. 2012; Khan and Safyan 2014) according to father-son logic. In an ontologies structure to transfer the property from "father" to "son", i.e., from class to subclasses, is an important characteristic to describe correctly the classes. Properties (functional, transitive, symmetric, or asymmetric, reflexive or irreflexive) are used to define the domain and the range of classes, as well as to describe and define the classes.

Ontology notion derives from classical philosophy and means "study of the Being". Categories are used to describe the properties and relationships of the "Being”. Ontology is an explicit specification of a conceptualization (Gruber 1992), so according to the sentence that "what exists can be represented" ontology concept has been transferred in other disciplines such as Physics and Computer Science. In the latter field, an ontology defines a common vocabulary for sharing information in a domain (Noy and McGuinness 2001). Therefore, the term "ontology", transferred from the language of logic to the language of semantic web, expresses that formalization, which enables to describe in the most complete and faithful way the characteristic concepts and relationships of a given knowledge domain. As conservation and valorization of built cultural heritage are complex activities, in which diverse subjects operate using different languages, a well-defined conceptualization is a mandatory condition for avoiding misunderstanding and waste. This may entail all the risks embodied in schematization, but it is also necessary for enabling any information exchange.

BuildingSMART International encourages several working groups in the definition of more and more efficient IFC standards, in order to extend interoperability to infrastructure, but also to landscape, etc., always as open standards. Currently, the specific needs of heritage buildings seem to be out of the scope, leaving the option to give up, or to continue in the development of a Historic BIM, which proposes a careful modelling, but in the reality reduces the historic building to the same logic of a new one. The scientific gap to be filled can be identified in the immaturity and limitedness of the specific ontologies and IFC standards and in their inadequacy to represent in an exhaustive and effective way the activities on built cultural heritage. 
The topic of ontologies has been developed at different levels in the various implementation fields. The use of ontologies for heritage, which requires a clear understanding of the cultural values and of the reasons of decay, has been definitely established in the field of museums (CIDOC-CRM) (Le Boeuf et al. 2018), while it is still object of research in the field of archaeology (CIDOC archaeo e CIDOC ba [Nicolucci 2015]).

The elaboration of a dedicated ontology adds the opportunity to fill typical conservation issues into HBIM models (Cacciotti et al. 2015; Zalamea et al. 2018; Beltramo et al. 2019) and to make the data embodied in Spatial Geographic Systems available to other kind of software, beginning from HBIM Systems (Acierno et al. 2017; Fiorani 2019; Acierno and Fiorani 2019).

The relationship between GIS and BIM platforms has been widely studied and further developed. Nevertheless, the challenge of sharing data and exchanging information through the two domains is still open. In fact, the accustomed syntactic approaches targeted to such integration do not allow a complete exchange of semantic and geometric information from BIM to GIS field and vice versa. It is worthy to point out the recent study on the $14 \mathrm{c}$. bridge across the Adda River at Lecco, which besides the elaboration of the HBIM themes of 3D survey and parametric modelling through NURBS (Barazzetti et al. 2016), has developed the topic of linking BIM model and geospatial data useful in the infrastructure domain (Barazzetti and Banfi 2017). The relationship ifcOWL-CityGML is being further explored in several ongoing researches (Matrone et al. 2019).

The new target is to formulate a systematic proposal of IFC standards compatible with the most used ontologies for the management of geospatial data, fundamental in the cultural heritage sector. An implementation of such an interoperable knowledge management can be developed with focus on prevention, a key activity, whose lack often causes dramatic losses. Making prevention, that is managing risks, requires exactly the possibility to cross geospatial data on hazard and exposure, with vulnerability data, which are usually referred to single properties and produced through correct maintenance activities; on the other hand, an operating prevention can be carried on both through interventions on the environment and strengthening works on single buildings: therefore, through actions requiring the cooperation of diverse actors. Thus, the needed step goes towards an effective data sharing, in order to support the decision-making process and to share the program of the interventions. Interoperability concerns the management of data as well as the repercussion on the processes.

\section{References}

Acierno M, Fiorani D (2019) Innovative tools for managing historical buildings: the use of geographic information system and ontologies for historical centers. Int Arch Photogramm Remote Sens Spatial Inf Sci XLII-2/W11:21-27. https://doi.org/10.5194/isprs-archives-XLII-2-W11-212019 
Acierno M, Cursi S, Simeone D, Fiorani D (2017) Architectural heritage knowledge modelling: an ontology-based framework for conservation process. J Cultural Heritage 24:124-133

Barazzetti L (2016) Parametric as-built model generation of complex shapes from point clouds. Adv Eng Inform 30:298-311

Barazzetti L, Banfi F (2017) BIM and GIS: when parametric modeling meets geospatial data. In: ISPRS annals of the photogrammetry, remote sensing and spatial information sciences, Geospace 2017, vol IV-5/W1, 4-6 Dec 2017, Kyiv, Ukraine, pp 1-8. https://doi.org/10.5194/isprs-annalsIV-5-W1-1-2017

Barazzetti L, Banfi F, Brumana R, Gusmeroli G, Oreni D, Previtali M, Roncoroni F, Schiantarelli G (2015) BIM from laser clouds and finite element analysis: combining structural analysis and geometric complexity. In: The international archives of the photogrammetry, remote sensing and spatial information sciences, vol XL-5/W4, 2015 3D virtual reconstruction and visualization of complex architectures, Feb 2015, pp 25-27, Avila, Spain

Barazzetti L, Banfi F, Brumana R, Previtali M, Roncoroni F (2016) BIM from laser scans... not just for buildings: NURBS-based parametric modeling of a medieval bridge. ISPRS Ann Photogramm Remote Sens Spatial Inf Sci III-5:51-56. https://doi.org/10.5194/isprs-annals-iii-5-51-2016

Beltramo S, Diara F, Rinaudo F (2019) Evaluation of an integrative approach between HBIM and architecture history. Int Arch Photogramm Remote Sens Spatial Inf Sci XLII-2/W11:225-229. https://doi.org/10.5194/isprs-archives-XLII-2-W11-225-2019

Brumana R, Della Torre S, Previtali M, Barazzetti L, Cantini L, Oreni D, Banfi F (2018) Generative HBIM - modeling to embody complexity: surveying, preservation, site intervention. The Basilica di Collemaggio (L'Aquila). In: Applied geomatics, 1 SI: Geomatics and restoration, Springer, pp $545-567$

Brumana R, Banfi F, Cantini L, Previtali M, Della Torre S (2019) HBIM level of detail—geometryaccuracy and survey analysis for architectural preservation. Int Arch Photogramm Remote Sens Spatial Inf Sci XLII-2/W11:293-299, https://doi.org/10.5194/isprs-archives-XLII-2-W11-2932019

Bruseker G, Guillelm A, Carboni N (2017) Cultural heritage data management: the role of formal ontology and CIDOC-CRM. In: Vincent ML et al (eds) Heritage and archeology in digital age. Quantitative methods in the humanities and social sciences. Springer, Berlin

Cacciotti R, Blasko M, Valach J (2015) A diagnostic ontological model for damages to historical constructions. J Cult Herit 16:40-48

Della Torre S (2017) Un bilancio del progetto BHIMM. In: Della Torre S (ed) Modellazione e gestione delle informazioni per il patrimonio edilizio esistente. INGENIO-WEB, pp 1-6

Della Torre S (2018) The management process for built cultural heritage: preventive systems and decision making. In: Van Balen K, Vandesande A (eds) Innovative built heritage models-reflections on cultural heritage theories and practices, CRC Press-Taylor and Francis Group, London, pp 13-20. ISBN 9781138498611

Della Torre S, Moioli R, Pili A (2018) Digital tools supporting conservation and management of built cultural heritage. In: Van Balen K, Vandesande A (eds) Innovative built heritage modelsreflections on cultural heritage theories and practices. CRC Press-Taylor and Francis Group, London, pp 101-106. ISBN 9781138498611

Della Torre S, Mirarchi C, Pavan A (2017) Il BIM per la conservazione, Rappresentare e gestire la conoscenza. ANANKE 82:108-115

Doerr M (2009) Ontologies for cultural heritage. In: Staab S, Studer R (eds) Handbook on ontologies. Springer, Berlin, pp 463-486

Dore C, Murphy M (2013) Semi-automatic modelling of building façades with shape grammars using historic building information modelling. In: International archives of the photogrammetry, remote sensing and spatial information sciences, 3D-ARCH 2013-3D virtual reconstruction and visualization of complex architectures, 25-26 Feb 2013, vol XL-5/W1, Trento, Italy

Eastman C, Teicholz P, Sacks R, Liston K (2011) BIM handbook: a guide to building information modeling for owners, managers, designers, engineers and contractors, 2nd edn. Wiley, Hoboken 
Fassi F, Achille C, Mandelli A, Rechichi F, Parri S (2015) A new idea of BIM system for visualization, web sharing and using huge complex 3D models for facility management. Int Arch Photogramm Remote Sens Spatial Inf Sci XL-5/W4:359-366. https://doi.org/10.5194/isprsarchivesxl-5-w4-359-2015

Fiorani D (2019) Il futuro dei centri storici. Digitalizzazione e strategia conservativa. Roma. Edizioni Quasar. ISBN 978-88-7140-925-2

Fregonese L, Rosina E, Adami A, Bottacchi MC, Romoli E, Lattanzi D (2018) Monitoring as strategy for planned conservation: the case of Sant'Andrea in Mantova (Mantua). Appl Geom 10(4):441-451

Gholami E, Kiviniemi A, Sharples S (2015) Implementing building information modelling (BIM) in energy efficient domestic retrofit: quality checking of BIM model. In: Proceedings of the 32nd CIB W78 conference 2015, 27th-29th 2015, Eindhoven, The Netherlands

Gruber TR (1992) A translation approach to portable ontology specification. Knowledge system laboratory, Technical Report KSL, pp 92-71

Khan S, Safyan M (2014) Semantic matching in hierarchical ontologies. J King Saud Univ Comput Inf Sci 26:247-257

Kiviniemi A, Codinhoto R (2014) Challenges in the implementation of BIM for FM-case Manchester Town Hall complex. In: Computing in civil and building engineering

Kupcík M, Šír M, Bradác Z (2012) Interoperability through ontologies. In: Programmable devices and embedded systems, pp 196-200

Laakso M, Kiviniemi A (2012) The IFC standard-a review of history, development, and standardization. J Inf Technol Constr (ITcon)” 17:134-161. http://www.itcon.org/2012/9

Le Boeuf P, Doerr M, Ore CE, Stead S (2018) CIDOC-conceptual reference model, definition. Version 6.2.3

Matrone F, Colucci E, De Ruvo V, Lingua A, Spanò A (2019) HBIM in a semantic 3D GIS database. Int Arch Photogramm Remote Sens Spatial Inf Sci XLII-2/W11:857-865. https://doi.org/10. 5194/isprs-archives-XLII-2-W11-857-2019, 2019

Musso SF, Franco G (2014) The "Albergo dei Poveri" in Genova: conserving and using in the incertainty and in the provisional. In: Della Torre S (ed) ICT per il miglioramento del processo conservativo. Firenze, Nardini, pp 41-50

Napoleone L (2017) Ricerca storica e sistema informativo: l'Albergo dei Poveri di Genova. In: Della Torre S (ed) Modellazione e gestione delle informazioni per il patrimonio edilizio esistente, INGENIO-WEB, pp 508-518

Nicolucci F (2015) Un'infrastruttura di ricerca per l'archeologia: il progetto Ariadne. Archeologia e calcolatori, suppl. 7:44

Noardo F (2015) Ontologie e modelli di dati per l'informazione spaziale dei Beni Architettonici. ASITA 2015:893-900

Noy NF, McGuinness DL (2001) Ontology development 101: a guide to creating your first ontology. In: Knowledge systems laboratory, pp 32

Oreni D, Brumana R, Cuca B, Georgopoulos A (2013) HBIM for conservation and management of built heritage: towards a library of vaults and wooden beam floors. In: CIPA 2013 XXV international symposium, ISPRS Annals, vol 164, pp 1-6

Oreni D, Brumana R, Della Torre S, Banfi F, Barazzetti L, Previtali M (2014) Survey turned into HBIM: the restoration and the work involved concerning the Basilica di Collemaggio after the earthquake (L'Aquila). In: ISPRS annals of the photogrammetry, remote sensing and spatial information sciences, technical commission v symposium, vol II, 23-25 giugno, Riva del Garda, pp 267-273

Rothenberg J (1989) The nature of modeling. In: AI, simulation \& modeling, pp 75-92

Trani M, Cassano M, Della Torre S, Bossi B (2015) Construction site information modelling and operational planning. In: Heritage and technology mind knowledge experience-Le Vie dei Mercanti_XIII Forum Internazionale di Studi, pp 1383-1392 
Vecchiattini R, Babbetto R (2017) I tiranti metallici preindustriali nella modellazione BIM di edifici in muratura. Dalla conoscenza alla rappresentazione parametrica. In: Della Torre S (ed) Modellazione e gestione delle informazioni per il patrimonio edilizio esistente, INGENIO-WEB, pp 355-369

Volk R, Stengel J, Schultmann F (2014) Building Information Modeling (BIM) for existing buildings-literature review and future needs. Autom Constr 38:109-127. https://doi.org/10.1016/j. autcon.2013.10.023

Zalamea O, Van Orshoven J, Steenberghen T (2018) Knowledge-based representations applied to built cultural heritage. In: Van Balen K, Vandesande A (eds) Innovative built heritage models. CRC Press and Balkema, Leiden, pp 93-100

Open Access This chapter is licensed under the terms of the Creative Commons Attribution 4.0 International License (http://creativecommons.org/licenses/by/4.0/), which permits use, sharing, adaptation, distribution and reproduction in any medium or format, as long as you give appropriate credit to the original author(s) and the source, provide a link to the Creative Commons license and indicate if changes were made.

The images or other third party material in this chapter are included in the chapter's Creative Commons license, unless indicated otherwise in a credit line to the material. If material is not included in the chapter's Creative Commons license and your intended use is not permitted by statutory regulation or exceeds the permitted use, you will need to obtain permission directly from the copyright holder. 